\title{
High Efficacy and Low Toxicity of Weekly Docetaxel Given as First-Line Treatment for Metastatic Breast Cancer
}

\author{
J. Stemmler ${ }^{a}$ W. Mair ${ }^{c}$ M. Stauch ${ }^{d} \quad$ J. Papke $\quad$ G. Deutsch ${ }^{f}$ W. Abenhardt ${ }^{c}$ \\ B. Dorn ${ }^{g}$ C. Kentenich ${ }^{b} \quad$ M. Malekmohammadi ${ }^{a} \quad$ C. Jackisch ${ }^{\text {h }}$ S. Leinung ${ }^{i}$ \\ O. Brudler ${ }^{j}$ U. Vehling-Kaiser ${ }^{k} \quad J$. Stamp $^{\prime}$ V. Heinemann ${ }^{\mathrm{a}}$
}

${ }^{a}$ Medical Department III and ${ }^{b}$ Department of Gynecology, University of Munich, ${ }^{c}$ Oncologic Practice, Munich,

${ }^{\mathrm{d}}$ Oncologic Practice, Kronach, ${ }^{e}$ Oncologic Practice, Neustadt, ${ }^{f}$ Diakonissenkrankenhaus, Karlsruhe,

${ }^{g}$ Academic Teaching Hospital, Aschaffenburg, h Department of Gynecology, University of Münster, Münster,

i Oncologic Practice, Leipzig, 'Oncologic Practice, Augsburg, ${ }^{\mathrm{k} O n c o l o g i c}$ Practice, Landshut, and 'Aventis,

Bad Soden, Germany

\section{Key Words}

Docetaxel $\cdot$ Breast cancer, metastatic $\cdot$ Chemotherapy

\begin{abstract}
Background: Docetaxel is one of the most effective antitumor agents currently available for the treatment of metastatic breast cancer (MBC). This phase II multicenter study prospectively analyzed the efficacy and toxicity of docetaxel given on a weekly schedule as first-line treatment of metastatic breast cancer. Patients and Methods: All patients received docetaxel, $35 \mathrm{mg} / \mathrm{m}^{2}$ weekly for 6 weeks, followed by 2 weeks of rest. Subsequent cycles ( 3 weeks of treatment, 2 weeks of rest) were given until a maximum of 5 cycles or disease progression. Premedication consisted of $8 \mathrm{mg}$ dexamethasone intravenously 30 min prior to the infusion of docetaxel. Results: Fiftyfour patients at a median age of 58 years with previously untreated MBC were included in the study. A median of 10 doses (median cumulative dose $339 \mathrm{mg} / \mathrm{m}^{2}$ ) was administered (range: 2-18). The overall response rate was $48.1 \%$ (95\% Cl: $34-61 \%$, intent-to-treat). Median survival was 15.8 months and median time to progression was 5.9 months (intent-to-treat). Hematological toxicity
\end{abstract}

was mild with absence of neutropenia-related complications. Grade 3 neutropenia was observed in $3.7 \%$ of patients and grade 3 and 4 anemia was observed in 5.6 and $1.9 \%$ of patients, respectively. Conclusion: The weekly administration of docetaxel is highly efficient and safe as first-line treatment for MBC and may serve as an important treatment option specifically in elderly patients and patients with a reduced performance status.

Copyright (C) 2005 S. Karger AG, Basel

\section{Introduction}

Docetaxel (Taxotere ${ }^{\circledR}$, Aventis, Bad Soden, Germany) is one of the most effective antitumor agents currently available for the treatment of metastatic breast cancer (MBC). When compared with the gold standard doxorubicin, docetaxel showed a significantly superior response rate $(47.8$ vs. $33.3 \%, p=0.008)$ and a trend towards a prolonged time to tumor progression ( 26 vs. 21 weeks) [1]. After failure of anthracycline-containing chemotherapy, single-agent docetaxel has demonstrated superior results when compared with mitomycin/vinblastine [response, time to progression (TTP), survival] or metho-

\section{KARGER}

Fax +4161306 1234 E-Mail karger@karger.ch www.karger.com
(C) 2005 S. Karger AG, Basel 0030-2414/05/0681-0071\$22.00/0

Accessible online at:

www.karger.com/ocl
PD Dr. med. V. Heinemann, University of Munich

Klinikum Grosshadern - Medical Department III (Hematology-Oncology)

Marchioninistrasse 15, DE-81377 Munich (Germany)

Tel. +49897095 2208, Fax +498970955256

E-Mail Volker.Heinemann@med.uni-muenchen.de 
trexate/5-fluorouracil (response, TTP) [2, 3], and has shown equivalent efficacy when compared with vinorelbine/5-fluorouracil (response, TTP, survival) [4].

The major rationale of a weekly schedule is the marked reduction of hematological toxicity [5-8]. When docetaxel is administered at a dose of $100 \mathrm{mg} / \mathrm{m}^{2}$ every 3 weeks, $70-90 \%$ of patients develop grade $3 / 4$ neutropenia. In previously reported phase II studies, severe (grade 3/4) hematological toxicity was uncommon at doses less than $40 \mathrm{mg} / \mathrm{m}^{2}$ given on a weekly basis [5-8]. The response rate achieved in these studies for pretreated patients ranged from 25 up to $41 \%$ [5-8].

An additional rationale for weekly docetaxel might be an equivalent dose intensity of treatment compared with the 3-weekly administration of docetaxel at a standard dose of $100 \mathrm{mg} / \mathrm{m}^{2}$. However, in pretreated and elderly patients, the 3 -weekly dose of $100 \mathrm{mg} / \mathrm{m}^{2}$ frequently needs to be adjusted to $75 \mathrm{mg} / \mathrm{m}^{2}[9,10]$. Given the improved tolerability of the weekly schedule, an increase of dose intensity may be achieved specifically in these patients [5-8].

While numerous studies have evaluated the weekly application of docetaxel in pretreated patients, this is the first report to analyze the efficacy and toxicity of weekly docetaxel in first-line therapy of MBC.

\section{Patients and Methods}

\section{Patient Selection}

Fifty-four patients with MBC were recruited. None of the patients had received chemotherapy for metastatic disease. The treatment protocol was approved by the local ethics committee and all patients gave written informed consent before treatment was started.

Patients were required to have histologically proven $\mathrm{MBC}$, bidimensionally measurable disease, a WHO performance status of $0-2$, be aged between 18 and 70 years, and have an anticipated survival of at least 12 weeks. Cardiac, hepatic, renal and hematological function had to be adequate [leukocyte count $\geq 3.0 \times$ $10^{9} / 1$; platelets $\geq 100 \times 10^{9} / 1$; hemoglobin $\geq 8 \mathrm{~g} / \mathrm{dl}$; bilirubin $\leq 1.25 \times$ normal range; ALT:AST (alanine aminotransferase:aspartate aminotransferase) ratio $\leq 3 \times$ normal range; alkaline phosphatase $\leq 2.5 \times$ normal range]. Patients with only bone metastases were not eligible for the trial. Additional exclusion criteria were radiotherapy of more than $25 \%$ of marrow-containing bone, brain metastases, previous neuropathy $\geq$ grade 2 , and a history of a second malignancy other than resected basal cell and/or squamous cell carcinoma of the skin.

\section{Treatment Regimen}

Patients were treated with a weekly dose of $35 \mathrm{mg} / \mathrm{m}^{2}$ docetaxel for 6 weeks, followed by 2 weeks of rest. Further treatment cycles were performed with a modified schedule, where docetaxel was ad- ministered on days 1,8 and 15 every 29 days (cycle 2 started on day 50$)$. Docetaxel $\left(35 \mathrm{mg} / \mathrm{m}^{2}\right.$ in $\left.100 \mathrm{ml} 0.9 \% \mathrm{NaCl}\right)$ was given by intravenous (i.v.) infusion over $30 \mathrm{~min}$. Premedication consisted of $8 \mathrm{mg}$ dexamethasone given i.v. $30 \mathrm{~min}$ before the start of docetaxel infusion.

Treatment was continued until either progression of disease, demonstration of severe side effects, or up to a maximum of 18 single doses of docetaxel ( 5 cycles).

In case of myelosuppression (leukocyte count $\leq 3,000 / \mu 1$, platelet count $\leq 100,000 / \mu \mathrm{l}$ ) on the day of planned treatment, further drug administration was postponed for 1 week until bone marrow recovery occurred. A full dose of docetaxel was administered if the blood counts had risen to leukocytes $\geq 3,000 / \mu l$ and platelets $\geq 100,000 / \mu 1$. Dose reductions for toxicity were $30 \mathrm{mg} / \mathrm{m}^{2}$ (level -1 ) and $25 \mathrm{mg} / \mathrm{m}^{2}$ (level -2 ). The dose was reduced by one level for nonhematological toxicity $\geq$ grade 3 (excluding alopecia and nausea/vomiting) or hematological toxicity grade 3 or 4 complicated by fever or infection or both. There was a maximum of two dose reductions per patient.

\section{Data Collection}

Drug administration, performance status and toxicity or adverse events were recorded after every cycle of docetaxel treatment. Weekly blood counts were performed. Febrile neutropenia was defined as fever $\left(\geq 38^{\circ} \mathrm{C}\right)$ with grade 4 neutropenia requiring i.v. antibiotics and/or hospitalization without documented infection. Fluid retention included peripheral edema and/or pleural and pericardial effusions.

Toxicity was graded according to the National Cancer Institute Common Toxicity Criteria [11]. Imaging studies using ultrasonography, computed tomography (CT), and magnetic resonance imaging (MRI) were performed after every two cycles of docetaxel treatment.

\section{Response Evaluation}

In all patients, tumors were measured by physical examination, imaging procedures such as CT or MRI within 14 days prior to entry into the study and subsequently after every two cycles of treatment. Standard evaluation by history, physical examination and routine laboratory tests (including complete blood cell count, chemistry profile and electrolyte determination) was performed before each treatment.

Patient response was assessed by standard WHO criteria, as follows complete response (CR) was defined as the disappearance of all known disease, as determined by two observations not less than 4 weeks apart, while partial response (PR) was defined as a decrease by at least $50 \%$ of the sum of the products of the largest perpendicular diameters of all measurable lesions, as determined by two observations not less than 4 weeks apart. Stable disease (SD), lasting for at least 6 weeks from the start of study (i.e. first drug administration), was defined as $<50 \%$ decrease and $<25 \%$ increase in the sum of the products of the largest perpendicular diameters of all measurable lesions. Progressive disease (PD) was a $>25 \%$ increase in the size of at least one bidimensionally or unidimensionally measurable lesion, or the appearance of a new lesion. The occurrence of pleural effusion was considered to be a sign of progression if it could be substantiated by positive cytology. 
Survival and TTP

TTP was determined by the interval between the initiation of therapy and the first date when disease progression was objectively documented. Overall survival was measured from the date of treatment start to the date of death from any cause. All patients were included for the analysis of TTP and survival (intent-to-treat).

\section{Statistical Methods}

The primary study end point was response rate. Probability of survival and time to progression were estimated by Kaplan-Meier analysis, and confidence intervals for response rates were calculated using methods for exact binominal confidence intervals [12, $13]$.

\section{Results}

\section{Patient Characteristics}

Patient characteristics are presented in table 1.

\section{Efficacy}

In an intent-to-treat analysis $6 \mathrm{CR}(11.1 \%), 20 \mathrm{PR}$ (37.0\%), 15 SD (27.8\%) and 10 PD (18.5\%) were observed. Three patients $(5.6 \%)$ were not evaluable. The overall response rate was $48.1 \%$ (95\% CI: 34-61\%). Among 41 patients who had received adjuvant chemotherapy, there were 5 CR (12.2\%), 16 PR (39.0\%), 10 SD (24.4\%) and 7 PD (17.1\%). Three patients (7.3\%) were not evaluable. The overall response rate in this subgroup was $51.2 \%$ (95\% CI: 35-67\%). The clinical benefit rate, defined as patients who achieved a CR or PR and patients who achieved a stabilization of the disease (CR + PR + $\mathrm{SD})$, amounts to $75.9 \%$ (95\% CI: $64-88 \%)$.

The response data are presented in detail in table 2.

Survival data were available for all patients with a median follow-up period of 16.2 months. The median TTP was 5.9 months and the median overall survival amounts to 15.8 months (fig. 1, 2).
Table 1. Patient characteristics

\begin{tabular}{lc}
\hline Characteristic & Patients \\
\hline Patients & 54 \\
\hline Age, years & \\
Median & 58 \\
Range & $37-80$ \\
$\geq 65$ years & 21 \\
\hline WHO performance status & \\
Median & 1 \\
0 & 18 \\
1 & 22 \\
2 & 14 \\
\hline Estrogen receptor status & \\
Positive & 26 \\
Negative & 24 \\
Unknown & 4 \\
\hline Measurable disease sites & 10 \\
Lung & 28 \\
Liver & 15 \\
Lymph nodes & 4 \\
Skin & 16 \\
Skeletal & 21 \\
\hline Number of disease sites per patient & 23 \\
1 & 10 \\
2 & 28 \\
\hline 3 & \\
\hline Prior treatment & \\
Adjuvant chemotherapy & \\
Adjuvant chemotherapy (anthracyclines) & \\
Adjuvant hormonal therapy & \\
Radiation & \\
Surgery & \\
Biopsy only (initially metastatic disease) & \\
\hline & \\
\hline & \\
\hline
\end{tabular}

Table 2. Efficacy (intent-to-treat; $n=54$ )

\begin{tabular}{|c|c|c|c|c|c|c|c|}
\hline & \multirow[t]{2}{*}{ Total, n } & \multirow[t]{2}{*}{$\mathrm{PR}, \mathrm{n}$} & \multirow[t]{2}{*}{$\mathrm{SD}, \mathrm{n}$} & \multirow[t]{2}{*}{$\mathrm{PD}, \mathrm{n}$} & \multirow{2}{*}{$\begin{array}{l}\text { Not } \\
\text { evaluable, } n\end{array}$} & \multicolumn{2}{|l|}{ OR } \\
\hline & & & & & & $\%$ & $95 \% \mathrm{CI}$ \\
\hline All & 54 & 20 & 15 & 10 & 3 & 48.1 & $34-61$ \\
\hline Adjuvant chemotherapy ${ }^{1}$ & 41 & 16 & 10 & 7 & 3 & 51.2 & $35-67$ \\
\hline $\begin{array}{l}\text { Adjuvant chemotherapy including } \\
\text { anthracyclines }{ }^{1}\end{array}$ & 26 & 11 & 4 & 6 & 1 & 57.7 & $37-78$ \\
\hline
\end{tabular}

${ }^{1}$ Percentage values are calculated relative to size of evaluable patients of subgroup. 


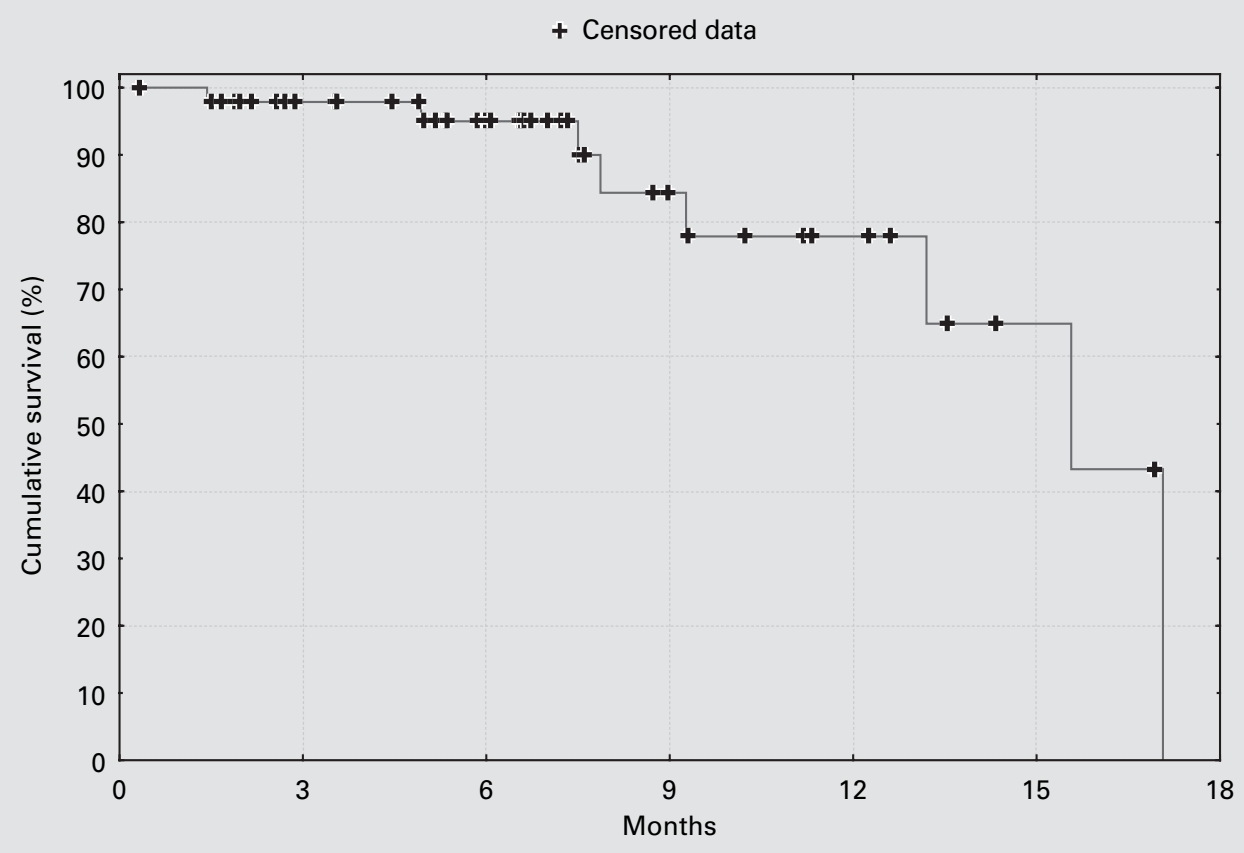

Fig. 1. Survival (intent-to-treat; $n=54$ ), median 15.8 months (range 0.3-17.1 months).



Fig. 2. TTP (intent-to-treat; $\mathrm{n}=54$ ), median 5.9 months (range $0.1-15.6$ months). 
Table 3. Toxicity profile of weekly administered docetaxel (per patient analysis, $n=54$ )

\begin{tabular}{lcccc}
\hline Toxicity & Grade $1, \%$ & Grade $2, \%$ & Grade $3, \%$ & Grade $4, \%$ \\
\hline Hematological toxicity & & & & \\
Neutropenia & $18.5(12.1$ vs. 9.5$)$ & $18.5(12.1$ vs. 9.5$)$ & $3.7(6.1$ vs. 0$)$ & - \\
Febrile neutropenia & - & - & - & - \\
Anemia & $25.9(24.2$ vs. 28.6$)$ & $13(12.1$ vs. 14.3$)$ & $5.6(6.1$ vs. 4.8$)$ & $1.9(3.0$ vs. 0$)$ \\
Thrombocytopenia & $5.6(6.1$ vs. 4.8$)$ & $3.7(6.1$ vs. 0$)$ & $1.9(3.0$ vs. 0$)$ & - \\
\hline Nonhematological toxicity & & & & - \\
Alopecia (grade 0-2) & $16.7(18.2$ vs. 14.3$)$ & $40.1(45.0$ vs. 33.3$)$ & - & - \\
Asthenia & $7.4(6.1$ vs. 9.5$)$ & $5.6(3.0$ vs. 9.5$)$ & $5.6(9.1$ vs. 0$)$ & - \\
Conjunctivitis/lacrimation & $5.6(3.0$ vs. 9.5$)$ & $5.6(6.1$ vs. 4.8$)$ & - & - \\
Diarrhea & $9.3(12.1$ vs. 4.8$)$ & $3.7(3.0$ vs. 4.8$)$ & $3.7(3.0$ vs. 4.8$)$ & - \\
Fever & $3.7(3.0$ vs. 4.8$)$ & $1.9(3.0$ vs. 0$)$ & - & - \\
Fluid retention/edema/effusions & - & $13.0(21.2 \text { vs. } 0)^{\mathrm{a}}$ & $1.9(3.0 \text { vs. } 0)^{\mathrm{b}}$ & - \\
Infection (not neutropenia-related) & $5.6(6.1$ vs. 4.8$)$ & - & $3.7(6.1$ vs. 0$)$ & - \\
Mucositis & $16.7(18.2$ vs. 14.3$)$ & - & $3.7(0$ vs. 9.5$)$ & - \\
Nail disorders & $5.6(3.0$ vs. 9.5$)$ & $5.6(6.1$ vs. 4.8$)$ & $1.9(3.0$ vs. 0$)$ & - \\
Nausea/vomiting & $18.5(12.1$ vs. 28.6$)$ & $3.7(3.0$ vs. 4.8$)$ & $3.7(6.1$ vs. 0$)$ & - \\
Neurotoxicity & $14.8(24.2$ vs. 0$)$ & $1.9(3.0$ vs. 0$)$ & - & - \\
Nose bleeding & $7.4(9.1$ vs. 4.8$)$ & - & - & - \\
Constipation & $3.7(3.0$ vs. 4.8$)$ & - & - & - \\
Pain (cancer-related) & $16.7(21.2$ vs. 9.5$)$ & $7.4(9.1$ vs. 4.8$)$ & $7.4(9.1$ vs. 4.8$)$ & - \\
Taste disturbance & $3.7(6.1$ vs. 0$)$ & - & - & - \\
\hline
\end{tabular}

Values in parentheses represent toxicity profile of younger patients $(<65$ years; $n=33)$ vs. elderly patients $(\geq 65$ years; $n=21)$; percentage values are calculated relative to the size of patients of subgroup.

a Edema: $\mathrm{n}=7$

${ }^{\mathrm{b}}$ Cytological positive pleural effusion in 1 patient.

Table 4. Toxicity profile of weekly administered docetaxel (653 single doses)

\begin{tabular}{|c|c|c|}
\hline & \multicolumn{2}{|c|}{ Single doses } \\
\hline & $\mathrm{n}$ & $\%$ \\
\hline \multicolumn{3}{|l|}{ Dose reduction } \\
\hline Dose level -1 (30 mg/m², weekly) & 20 & 3.1 \\
\hline Dose level $-2\left(25 \mathrm{mg} / \mathrm{m}^{2}\right.$, weekly $)$ & 7 & 1.1 \\
\hline \multicolumn{3}{|l|}{ Delayed doses } \\
\hline Total & 55 & 8.4 \\
\hline Due to cytopenia & 41 & 6.3 \\
\hline For other reasons & 14 & 2.1 \\
\hline
\end{tabular}

\section{Toxicity}

All investigated hematological and nonhematological toxicities are listed in table 3 . Only $3.7 \%$ of patients experienced severe neutropenia (grade 3) and no febrile neutropenia was observed. None of the patients required hematological growth factor support. Mild anemia was common (grade 1 and 2: 25.9 and 13\% of patients), but severe anemia was rarely noted including grade 3 and 4 anemia in 5.6 and $1.9 \%$ of patients. Severe thrombocytopenia was uncommon and was observed in only $1.9 \%$ of patients (grade 3).

Except fluid retention symptoms (grade 2) and neurotoxicity (grade 1) there were no significant differences regarding the toxicity profile in younger patients ( $<65$ years) versus elderly patients (age $\geq 65$ years).

A dose reduction of one dose level $\left(30 \mathrm{mg} / \mathrm{m}^{2}\right)$ was necessary in $3.1 \%$ of all administered doses $(n=653)$, while a second reduction $\left(25 \mathrm{mg} / \mathrm{m}^{2}\right)$ was required in only $1.1 \%$. Delayed applications of single doses were necessary in $8.4 \%$ (table 4 ).

\section{Discussion}

Docetaxel has shown high efficacy in first-line treatment of MBC yielding response rates up to $54 \%(95 \% \mathrm{CI}$ : $37-71 \%)$ and $67.7 \%$ (95\% CI: 49-83\%) when adminis- 
Table 5. Comparative analysis of hematological and nonhematological toxicity

\begin{tabular}{|c|c|c|c|c|}
\hline & \multicolumn{4}{|l|}{ Grade $3 / 4$ toxicity } \\
\hline & \multirow{2}{*}{$\begin{array}{l}\text { weekly regimen of } \\
\text { docetaxel } 35 \mathrm{mg} / \mathrm{m}^{2} \\
\text { this trial }\end{array}$} & \multicolumn{3}{|c|}{$\begin{array}{l}\text { 3-weekly regimen of docetaxel } \\
100 \mathrm{mg} / \mathrm{m}^{2}\end{array}$} \\
\hline & & $\begin{array}{l}\text { Chan } \\
\text { et al. [1] }\end{array}$ & $\begin{array}{l}\text { Nabholtz } \\
\text { et al. [2] }\end{array}$ & $\begin{array}{l}\text { Sjöström } \\
\text { et al. [3] }\end{array}$ \\
\hline Median cumulative dose, $\mathrm{mg} / \mathrm{m}^{2}$ & 339 & 679 & 564 & 570 \\
\hline \multicolumn{5}{|l|}{ Hematological, $\%$ of patients } \\
\hline Neutropenia & 3.7 & 93.5 & 93.1 & $77^{\mathrm{a}}$ \\
\hline Anemia & 7.5 & 4.4 & n.a. & 2 \\
\hline Thrombopenia & 1.9 & 1.3 & 4.1 & 3 \\
\hline Febrile neutropenia & 0 & 5.7 & 9 & n.a. \\
\hline \multicolumn{5}{|l|}{ Nonhematological, $\%$ of patients } \\
\hline Alopecia (grade 2) & 40.1 & n.a. & n.a. & 74 \\
\hline Asthenia & 5.6 & 14.5 & 16 & 12 \\
\hline Conjunctivitis/lacrimation & - & n.a. & n.a. & - \\
\hline Diarrhea & 3.7 & 10.7 & 7.5 & 10 \\
\hline Fluid retention overall & $1.9^{\mathrm{b}}$ & $6.3^{\mathrm{b}}$ & n.a. & 3 \\
\hline Infection & 3.7 & 2.5 & 11 & $26^{\mathrm{c}}$ \\
\hline Mucositis/stomatitis & 3.7 & 5 & 9 & 9 \\
\hline Nausea/vomiting & 3.7 & 3.1 & $4.5 / 2.5$ & 6 \\
\hline Neurotoxicity & - & $8^{\mathrm{d}}$ & $5^{\mathrm{e}}$ & 5 \\
\hline Skin/nail & $0 / 1.9$ & 1.9/n.a. & $4 / 2.5$ & $2 / 5$ \\
\hline
\end{tabular}

n.a. = Not available.

${ }^{\mathrm{a}}$ Leukopenia; ${ }^{\mathrm{b}}$ edema and pleural effusion; ${ }^{\mathrm{c}}$ includes febrile infection; ${ }^{\mathrm{d}}$ neurosensory plus neuromotor; ${ }^{\mathrm{e}}$ neurosensory. tered at a dose of $100 \mathrm{mg} / \mathrm{m}^{2}$ every 3 weeks [14-16]. In pretreated patients, docetaxel treatment resulted in response rates of $48-55 \%[1,9,10,17]$. When docetaxel was given after anthracycline failure, response rates of 30 $42 \%$ were achieved in two randomized trials [2, 3].

Although the 3-weekly regimen has proven a high level of antitumor activity, it is accompanied by considerable hematological toxicity. Grades 3-4 neutropenia was observed in up to $97 \%$ of patients $[1,9,10,17]$. Regarding these side effects, a dose reduction of docetaxel was recommended specifically in elderly and unfit patients $[9$, 10]. When docetaxel doses were reduced to $60-75 \mathrm{mg} / \mathrm{m}^{2}$ every 3 weeks, overall response rates of $33-35 \%$ were reported in pretreated patients with a moderate reduction of hematological side effects [10, 18, 19].

The administration of docetaxel at a weekly dose of $35-40 \mathrm{mg} / \mathrm{m}^{2}$ combines the advantages of a preserved dose intensity with a markedly reduced hematological toxicity relative to standard 3-weekly regimens [5-8]. The response rate achieved in phase II studies for pretreated patients ranged from 25 up to $41 \%$ [5-8]. But until now, there are no data of weekly docetaxel given as first-line treatment for MBC. In this trial of previously untreated patients for metastatic disease, docetaxel induced an overall response rate of $48.1 \%$ (95\% CI: $34-61 \%)$. The clinical benefit rate (CR + PR + SD) amounts to $75.9 \%$ (95\% CI: 64-88\%). A disease control was achieved in a limited time of cytotoxic treatment (median doses/patient $=10$ ), supporting the high efficacy of single-agent weekly docetaxel. In this trial, the median TTP was 5.9 months (range: 0.1-15.6), which was within the range of that reported for every three-week regimen (3-9 months) [14, 16, 17].

The standard regimen is accompanied by severe neutropenia in up to $97 \%$ leading to infections (including febrile neutropenia) in up to $26 \%$ of the patients. This potentially life-threatening toxicity may, however, be prevented by the application of docetaxel at weekly doses below $40 \mathrm{mg} / \mathrm{m}^{2}$ [5-8]. In fact, grade 3 and 4 hematological toxicity was reduced to $5 \%$ (grade 3 ) and $1 \%$ (grade 4) of patients [5-8]. In the present study, grade 3 and 4 neutropenia was observed in 3.7 and $0 \%$ of patients. Neu- 
tropenic fever was not observed and none of the patients required G-CSF support. The low number of dose reductions [dose level $-1\left(30 \mathrm{mg} / \mathrm{m}^{2}\right): 3.1 \%$; dose level -2 $\left.\left(25 \mathrm{mg} / \mathrm{m}^{2}\right): 1.1 \%\right]$ and treatment delays $(8.4 \%$ of cycles) also reflects the low hematological toxicity of this regimen.

Despite the marked difference in hematological toxicity, nonhematological side effects were not significantly different between the weekly and the 3-weekly schedule (table 5). The incidence of severe nonhematological toxicity was low.

Asthenia and fatigue were reported as the most common reason for dose reduction. In this study, grade 3 asthenia was reported only in $5.6 \%$ of patients. The lower weekly dose of $35 \mathrm{mg} / \mathrm{m}^{2}$ chosen in this study compared to the dose of $40 \mathrm{mg} / \mathrm{m}^{2}$ used by Burstein et al. [5] may explain the lower incidence of severe asthenia observed in this trial (table 5).

Conjunctivitis and lacrimation are also known sequelae of docetaxel treatment [20]. The incidence of $11.2 \%$ (grade 1 and 2 toxicity) in the present study is in good agreement with a previous report stating a $12 \%$ overall incidence in the 3-weekly regimen [3]. Also mucositis, stomatitis, and nausea occurred at similar frequencies compared to the 3-weekly regimen.

Due to the low emetogenic potential of weekly docetaxel, 5-HT 3 antagonists were not required on a routine basis.

Severe fluid retention symptoms occurred in $1.9 \%$ of patients (grade 3), which is in the range reported by other authors $[1,3]$.
To determine the toxicity profile of weekly docetaxel in younger ( $<65$ years) and elderly patients ( $\geq 65$ years) the incidence of side effects was presented for the whole study population and for each group separately (table 3 ). Except fluid retention symptoms and neurotoxicity, there were no significant differences regarding the toxicity profile in younger and elderly patients, which supports the feasibility of weekly docetaxel even in the elderly patients. The significantly increased incidence of fluid retention symptoms (grade 2) and neurotoxicity (grade 1) in the younger patients may be explained by the low number of patients in these subgroups.

This is the first trial that evaluated a weekly administration of docetaxel given as first-line treatment for MBC. The weekly schedule induced a high level of activity and was well tolerated. Compared to a standard 3-weekly regimen, the weekly regimen greatly reduced hematological toxicity. Specifically in elderly patients, where intensive chemotherapy is not feasible, a weekly administration of docetaxel may serve as an important treatment option. The limited duration of cytotoxic treatment in this trial (median 10 weeks) appears to be another argument for this schedule. Moreover, the short duration of drug administration (30 min) clearly supports the use of this regimen on an outpatient basis. Since conclusive data are missing, a randomized phase III study has been started to prospectively evaluate efficacy and safety of a 3-week versus a weekly schedule in elderly patients.

\section{References}

1 Chan S, Friedrichs K, Noel D, Pinter T, Van Belle S, Vorobiof D, Duarte R, Gil Gil M, Bodrogi I, Murray E, Yelle L, von Minckwitz G, Korec S, Simmonds P, Buzzi F, Gonzalez Mancha R, Richardson G, Walpole E, Ronzoni M, Murawsky M, Alakl M, Riva A, Crown $\mathrm{J}$ : Prospective randomized trial of docetaxel versus doxorubicin in patients with metastatic breast cancer. J Clin Oncol 1999;17:23412354.

2 Nabholtz JM, Senn HJ, Bezwoda WR, Melnnychuk D, Deschenes L, Douma J, Vandenberg TA, Rapoport B, Rosso R, Trillet-Lenoir V, Drbal J, Molino A, Nortier JWR, Richel DJ, Nagykalnai T, Siedlecki P, Wilking N, Genot JY, Hupperets PSGJ, Pannuti F, Skarlos D, Tomiak EM, Murawsky M, Alakl M, Riva A, Aapro M: Prospective randomized trial of docetaxel versus mitomycin $C$ plus vinblastine in patients with metastatic breast cancer pro- gressing despite previous anthracycline-containing chemotherapy. J Clin Oncol 1999;17: 1413-1424.

3 Sjöström J, Blomqvist C, Mouridsen H, Pluzanska A, Ottoson-Lönn S, Bengtsson NO, Ostenadt B, Mjaaland I, Palm-Sjöwall M, Wist E, Valvere V, Anderson H, Bergh J: Docetaxel compared with sequential methotrexate and 5fluorouracil in patients with advanced breast cancer after anthracycline failure: A randomised phase III study with crossover on progression by the Scandinavian Breast Group. Eur J Cancer 1999;35:1194-1201.

4 Bonneterre J, Roche H, Monnier A, Guastalla JP, Namer M, Frageot P, Assadourian S: Docetaxel vs. 5-fluorouracil plus vinblastine in metastatic breast cancer after anthracycline therapy failure. Br J Cancer 2002;87:1210 1215.
5 Burstein HJ, Manola J, Younger J, Parker LM, Bunnell CA, Scheib R, Matulonis UA, Garber JE, Clarke KD, Shulman LN, Winer EP: Docetaxel administered on a weekly basis for metastatic breast cancer. J Clin Oncol 2000;18: 1212-1219.

6 Stemmler HJ, Gutschow K, Sommer H, Malekmohammadi M, Kentenich C, Forstpointner R, Geuenich S, Bischoff J, Hiddemann W, Heinemann V: Weekly docetaxel (Taxotere) in patients with metastatic breast cancer. Ann Oncol 2001;12:1393-1398.

7 Aihara T, Kim Y, Takatsuka Y: Phase II study of weekly docetaxel in patients with metastatic breast cancer. Ann Oncol 2002;13:286-292. 
8 Hainsworth JD, Burris HA, Yardley DA, Bradof JE, Grimaldi M, Kalman LA, Sullivan T, Baker M, Erland JB, Greco FA: Weekly docetaxel in the treatment of elderly patients with advanced breast cancer: A Minnie Pearl Cancer Research Network phase II trial. J Clin Oncol 2001;19:3500-3505.

9 Salminen E, Bergman M, Huhtala S, Ekholm E: Docetaxel: Standard recommended dose of $100 \mathrm{mg} / \mathrm{m}^{2}$ is effective but not feasible for some metastatic breast cancer patients heavily pretreated with chemotherapy - A phase II singlecenter study. J Clin Oncol 1999;17:11271131.

10 O'Brien MER, Leonard RC, Barrett-Lee PJ, Eggleton SPH, Bizzari JP: Docetaxel in the community setting: An analysis of 377 breast cancer patients treated with docetaxel (Taxotere) in the UK. Ann Oncol 1999;10:205210.

11 Ajani JA, Welch SR, Raber MN, Fields WS, Krakoff IH: Comprehensive criteria for assessing therapy-induced toxicity. Cancer Invest 1990;8:147-159.

12 Kaplan EL, Meier P: Nonparametric estimation from incomplete observations. J Am Stat Assoc 1959;53:457-481.
13 Cox DR: The Analyses of Binary Data. London, Methuen, 1970.

14 Chevallier B, Fumoleau P, Kerbrat P, Dieras V, Roche H, Krakowski I, Azli N, Bayssas M, Lentz MA, Van Glabbeke M: Docetaxel is a major cytotoxic drug for the treatment of advanced breast cancer: A phase II trial of the clinical screening cooperative group of the EORTC. J Clin Oncol 1995;13:214-222.

15 Hudis CA, Seidman AD, Crown JP, Balmaceda C, Freilich R, Gilewski TA, Hakes TB, Currie V, Lebwohl DE, Baselga J, Raptis G, Gollup M, Robles M, Bruno R, Norton L: Phase II and pharmacologic study of docetaxel as initial chemotherapy for metastatic breast cancer. J Clin Oncol 1996;14/1:58-65.

16 Trudeau ME, Eisenhauer EA, Higgins BP, Letendre F, Lofters WS, Norris BD, Vandenberg TA, Delorme F, Muldal AM: Docetaxel in patients with metastatic breast cancer: A phase II study of the National Cancer Institute of Canada-Clinical Trials Group. J Clin Oncol 1996; 14:422-428.
17 Valero V, Jones SE, Von Hoff DD, Booser DJ, Mennel RG, Ravdin PM, Holmes FA, Rahman Z, Schottstaedt MW, Erban JK, EsparzaGuerra I, Earhart RH, Hortobagyi GN, Burris HR 3rd: A phase II study of docetaxel in patients with paclitaxel-resistant metastatic breast cancer. J Clin Oncol 1998;16:33623368.

18 Dieras V, Chevallier B, Kerbrat P, Krakowski I, Roche H, Misset JL, Lentz MA, Azli N, Murawsky M, Riva A, Pouillart P, Fumoleau P: A multicentre phase II study of docetaxel $75 \mathrm{mg} /$ $\mathrm{m}^{2}$ as first-line chemotherapy for patients with advanced breast cancer: Report of the clinical screening group of the EORTC. Br J Cancer 1996;74:650-656.

19 Ando M, Watanabe T, Nagata K, Narabayashi M, Adachi I, Katsumata N: Efficacy of docetaxel $60 \mathrm{mg} / \mathrm{m}^{2}$ in patients with metastatic breast cancer according to the status of anthracycline resistance. J Clin Oncol 2001;19:336-342.

20 Esmaeli B, Hortobagyi G, Esteva F, Valero V, Ahmadi MA, Booser D, Ibrahim N, Delpassand E, Arbuckle R: Canalicular stenosis secondary to weekly docetaxel: A potentially preventable side effect. Ann Oncol 2002;13: 218-221. 